\title{
Tom Cruise is dangerous and irresponsible
}

\begin{abstract}
Yes, even the JCI can weigh in on celebrity gossip, but hopefully without becoming a tabloid. Rather, we want to shine a light on the reckless comments actor Tom Cruise has recently made that psychiatry is a "quack" field and his belief that postpartum depression cannot be treated pharmacologically. We can only hope that his influence as a celebrity does not hold back those in need of psychiatric treatment.
\end{abstract}

Several interviews have aired in which Tom Cruise has publicized his disdain for psychiatry and the mental health profession (1, 2). In one interview, Cruise claimed to know the literature on the history of psychiatry, chemical imbalances, and Ritalin (methylphenidate), the attention-deficit hyperactivity disorder (ADHD) drug (1). In another, he called actress Brooke Shields irresponsible for publishing a book on her battle with and treatment of postpartum depression, since he believes vitamins and exercise are all that is needed for treatment (2).

Throughout these and other interviews, Cruise spewed a number of irresponsible statements, attempting to pass them off as facts. However, several of Cruise's statements are very easy to dispel as false.

With regard to the number of children currently taking drugs to control ADHD, Cruise is quoted as saying "[Psychiatrists] said, 'Oh, you know, Ritalin is safe. It's safe. It's safe.' Ritalin is an amphetamine" (2). The National Institute on Drug Abuse (NIDA) begs to differ. Ritalin (a stimulant, but not an amphetamine) has been shown to amplify the release of dopamine and thereby improve attention and focus in individuals who have weak dopamine signals, such as those with ADHD (3). NIDA goes on to note that ADHD patients do not become addicted to Ritalin or similar medications when taken in the form and dosage prescribed by doctors, and it has been reported that individuals with ADHD who are treated with Ritalin are significantly less likely than those who do not receive treatment to abuse drugs and alcohol when they are older (4).

Later in the same interview, Cruise discusses how he "recently helped a family have their daughter get off [ADHD] drugs ... We stepped the [7-year-old] child off the drugs, got her vitamins and food. She has calmed down now and she has grown seven inches in about four months" (2). If true, this child should be examined for growth abnormalities, as a normal growth spurt occurs during puberty (12-14 years old in females) and is on average 3-5 inches. Hyperbole on the part of Mr. Cruise, perhaps? One would hope the child was under the care of a medical doctor.

Cruise believes the education of children is suffering due to extensive Ritalin use. In connection to the drug, he said, "SAT scores have gone right down the toilet" (2). Not so, says the College Board, the non-profit organization that designs, administers, and evaluates the SAT (scholastic aptitude test) and PSAT (preliminary SAT) among other tests and advanced placement courses. In a recent article about trends in test scores, the College Board said, "Consistent with a decade-long trend, SAT math scores have continued to rise. In 2002, the average SAT math score rose two points to 516." The report does note that while "Verbal scores declined in 2002 [by 2 points] to an average of 504 for the entire test-taking population ... The average verbal score for 2002 is just 4 points higher than that of 1992" (5). I would dare say this report does not indicate that SAT scores are going down the toilet.

My favorite part of this interview was when Cruise equated psychiatrists to drug dealers. "You know what? I'm sure drug dealers on the street, in some way, they are making money. That's what I equate it to. Here is the thing: you have to understand, with psychiatry, there is no science behind it. And to pretend that there is a science behind it is criminal" (2). In Cruise's eyes, there are a lot of us criminals, including the 38,000 members of the American Psychiatric Association (APA), who have issued several statements disagreeing with many of Cruise's exhortations about the mental health field. I suppose now would also be an appropriate time to mention my particular conflict of interest - I am the daughter of a psychiatrist/neurologist. That said, my father, and most responsible physicians, are well-trained scientists who do not run around willy-nilly dispensing controlled substances nor filling irresponsible prescriptions to, in Cruise's words, "drug the piss" (2) out of their patients.
Though it is hard to believe Cruise has ample time to help legions of drug addicts, given his intense movie production and publicity responsibilities, it is admirable that he tries. But he goes on to say, "I have an easier time stepping people off heroin then I do these psychotropic drugs" (2). In his efforts to help drug abusers, Cruise supports the Scientology-based 9-step drug withdrawal program Narconon International (6). Step 3 of Narconon is called the "Purification Rundown," in which drug residues and other toxic substances are removed from the body through a regimen of exercise, sauna, and nutritional supplements. In 1989, Everett R. Rhoades, US assistant surgeon general, was quoted as saying the concepts behind Narconon could not be considered medically sound. Further, the Board of Mental Health in Oklahoma concluded in 1991 that the high doses of vitamins and minerals administered in the Purification Rundown could be potentially dangerous and therefore declined to certify the program. While it is commendable for any person with a drug addiction problem to seek help, state-certified, proven rehabilitation programs should be sought.

Let us move on to postpartum depression and chemical imbalances. Cruise pulls no punches when asked about his thoughts on the existence of chemical imbalances: he claims there is no scientific evidence to verify they exist, based on his reading of the scientific literature (1). When asked about drugs like Paxil for the treatment of postpartum depression, he spoke plainly: "Let me tell you something: it is not a cure and it is actually lethal. These drugs are dangerous ... There is a hormonal thing that is going on that is ... scientifically, you can prove that. But when you talk about emotional chemical imbalances in people, there is no science behind that" (2). Again, I beg to differ and so does 50 years' worth of literature (summarized in refs. 7,8 ). While indeed other theories have been proffered to explain depression, the idea that chemical or genetic imbalances may underlie depression has been widely accepted. I wonder how an actor with Cruise's educational background (no course of study noted past a high school degree) came to understand the medical literature and whether he would be conversant in the intricacies of 
the monoamine hypothesis or serotonin and noradrenaline signaling.

Brooke Shields said it best in her July 1 , 2005, New York Times Op-Ed column: "Comments like those made by Tom Cruise are a disservice to mothers everywhere. To suggest that I was wrong to take drugs to deal with my depression, and that instead I should have taken vitamins and exercised shows an utter lack of understanding about postpartum depression and childbirth in general" (9). Rather than Shields being the irresponsible one, I have found most women agree that it is Cruise's message that Paxil is lethal and that postpartum depression does not exist that is irresponsible.

In addition to his unusual thoughts on postpartum mothers, Cruise is assumed to share his religion's philosophy about care for newborn infants, another course of action not condoned by medical care professionals. Scientologists believe in the "Silent Birth" method, in which newborns are neither poked and prodded in medical tests nor even spoken to in the first 7 days of life. According to their theology, because babies go through so much pain during the birth process, newborn babies should not be subjected to any further pain or sensory experiences that could return later in life to haunt them. An Omaha-based couple even attempted to introduce a bill in the Nebraska legislature in 2003 exempting Scientologists from medical screening of newborns. I can find no medical literature on the benefits of silence in the first week of newborn life.

In terms of the Scientology view of medicine and mental health, I can only assume that Cruise follows the religion's principles. According to a primer on Scientology, followers generally shun conventional medicine as they believe illnesses are largely psychosomatic. Illness is a sign of weakness and failure, and followers are encouraged to treat their ailments with auditing (talking through issues while attached to a biofeedback device called an "E-meter" that is similar to a lie detector). Since all illness are psychosomatic in the eyes of a Scientologist, members believe that everything from indigestion to AIDS can be cured through auditing and vitamins. L. Ron Hubbard, the founder of Scientology and the author of their main text, Dianetics: the modern science of mental health (10), has been quoted as saying, "Leukemia is evidently psychosomatic in origin and at least eight cases of leukemia had been treated successfully by Dianetics after medicine had traditionally given up" (11). Further, he has claimed that "Arthritis vanishes, myopia gets better, heart illness decreases, asthma disappears, stomachs function properly and the whole catalogue of illnesses goes away and stays away [with Scientology]" (10). My personal favorite quote: "Scientology is the only specific (cure) for radiation (atomic bomb) burns" (12). It is unclear whether Scientologists continue to believe that auditing is superior to medical therapy, though it is clear that they do not condone the use of pharmacotherapy for mental illness.

But again, back to Tom Cruise. He continued in his Access Hollywood interview to make note of how popular his methods have been. "You just have no idea what it's like being me and all the people that want help. All the people that call that I talk to at 2 a.m. that ask for advice." He continued: "People know that they can call me. They are respectful, actually. They don't waste my time. They say, 'Look, I need help at this. What should I do?' And I help them. I have nothing to gain. I just want to see people do well. . . . I get so many letters from people thanking me. Thanking me for their children and for themselves" (2). Perhaps we should call Cruise and let him know what we think? Despite his eagerness to speak with people on the phone, I found it nearly impossible to find a phone number where I could reach him to get help with this editorial. But, should you decide to contact Cruise by mail, he can be reached care of Creative Artists Agency (9830 Wilshire Boulevard, Beverly Hills, California 90212, USA) or care of Church of Scientology International (6331 Hollywood Boulevard, Suite 1200, Los Angeles, California 90028, USA).

\section{Ushma S. Neill Executive Editor}

1. CNN.com. 2005. Cruise, Lauer argue on 'Today'. http://www.cnn.com/2005/SHOWBIZ/TV/06/24/ people.cruise.ap/.

2. Access Hollywood. 2005. Tom Cruise: man on a mission. http://www.accesshollywood.com/ news/4537415/detail.html.

3. National Institute on Drug Abuse. 2005. NIDA InfoFacts: methylphenidate (Ritalin). http://www. nida.nih.gov/Infofacts/Ritalin.html.

4. Mannuzza, S., Klein, R.G., and Moulton, J.L., III. 2003. Does stimulant treatment place children at risk for adult substance abuse? A controlled, prospective follow-up study. J. Child Adolesc. Psychopharmacol. 13:273-282.

5. College Board. 2002. 10-year trend in SAT scores indicates increased emphasis on math is yielding results; reading and writing are causes for concern. http://www.collegeboard.com/press/article/0,11752,00.html.

6. Narconon International Drug Prevention \& Rehabilitation. http://www.narconon.org/.

7. Nestler, E.J. et al. 2002. Neurobiology of depression. Neuron. 34:13-25.

8. Castrén, E. 2005. Is mood chemistry? Nat. Rev. Neurosci. 6:241-246.

9. Shields, B. 2005. War of words [op-ed]. New York Times. July 1.

10. Hubbard, L.R. 1987. Dianetics: the modern science of mental health. Bridge Publications. Los Angeles, California, USA. 72.

11. Hubbard, L.R. 1953. Journal of Scientology. Issue 15-G.

12. Hubbard, L.R., Denk, G., Spink, F.R., and Farley, R. 1957. All about radiation. Bridge Publications. Los Angeles, California, USA. 109. 